\title{
Spatial distribution and hatching of overwintered eggs of a fish ectoparasite, Argulus coregoni (Crustacea: Branchiura)
}

\author{
V. N. Mikheev ${ }^{1, *}$, A. F. Pasternak ${ }^{2}$, E. T. Valtonen ${ }^{3}$, Y. Lankinen ${ }^{4}$ \\ ${ }^{1}$ A.N. Severtsov Institute of Ecology \& Evolution, Russian Academy of Sciences, 33 Leninskii Prospekt, Moscow 117071, Russia \\ ${ }^{2}$ Institute of Oceanology, Russian Academy of Sciences, 36 Nakhimov Avenue, Moscow 117853, Russia \\ ${ }^{3}$ Department of Environmental and Biological Science, University of Jyväskylä, PL 35, 40351 Jyväskylä, Finland \\ ${ }^{4}$ Savon Taimen OY, 77700 Rautalampi, Finland
}

\begin{abstract}
The habitat distribution of overwintered eggs, which were found to be the only source of spring recruitment of Argulus coregoni Thorell, was studied at a commercial fish farm in Central Finland. The frequency of occurrence of egg clutches in the deep parts of the canals and ponds was 50 to $80 \%$ and the percentage cover of the surface of stones with egg clutches was 1.7 to $6.4 \%$, while in the shallow parts these values were 8 to $27 \%$ and 0.1 to $0.3 \%$, respectively. A greater proportion of empty egg-shells was observed in shallow water in the mid-May, suggesting an earlier hatching there stimulated by the increased temperature and higher illumination. Under laboratory conditions, only elevated UV illumination, but not diurnally fluctuating temperature, significantly accelerated hatching. Normally overwintered eggs produced a pronounced peak of hatched larvae at the end of May and hatching continued at a much slower rate throughout the summer. Eggs that overwintered twice, first normally and then for a second time buried under sediments, were exposed to the same laboratory conditions simultaneously with normally overwintered eggs, but their hatching was delayed until August. The hatching rate was low, but markedly increased in December.
\end{abstract}

KEY WORDS: Overwintering $\cdot$ Argulus coregoni $\cdot$ Ectoparasite $\cdot$ Egg distribution $\cdot$ Hatching

Resale or republication not permitted without written consent of the publisher

\section{INTRODUCTION}

Overwintering is the crucial period in the life cycle of aquatic animals in boreal communities. In argulid crustaceans, which are obligate fish ectoparasites, the overwintering stages have not been well described. Two argulid species, Argulus coregoni Thorell and A. foliaceus, often coexist in lakes and fish farms in Finland. The latter species is much better studied with respect to its ecology and life cycle (Bower-Shore 1940, Kollatsch 1959, Stammer 1959, Bauer 1970, Pasternak et al. 2000). In $A$. foliaceus, overwintering was described both for the adult stages (Bower-Shore 1940, Hindle 1949, Bauer 1970) and resting eggs (Bower-

*E-mail: avamik@online.ru
Shore 1940, Kollatsch 1959, Stammer 1959, Bauer 1970, Pasternak et al. 2000). Shimura (1983) in his thorough ecological study of $A$. coregoni in Japan $\left(36^{\circ} \mathrm{N}\right)$ found that parasites overwintered as eggs and that there were 1 or 2 generations $\mathrm{yr}^{-1}$.

Despite the serious problems that Argulus coregoni sometimes causes at salmonid fish farms in Finland, its life cycle and particularly its overwintering strategy have not been studied in northern latitudes. In our preliminary observations, we noted a pronounced peak of small $A$. Coregoni larvae at the end of May and the beginning of June, but their source was unknown. To establish effective control measures in early spring, before infection spreads, it is necessary to know the overwintering stages and their distribution. If eggs are the main overwintering stage, one has to know the patterns of hatching, which may be affected by a vari- 
ety of environmental factors. Hatching of $A$. japonicus eggs was found to be faster and the proportion of hatched eggs greater under fluctuating temperatures (Shafir \& van As 1986). A stimulating effect of sunlight on hatching was suggested (Kollatsch 1959).

The main objectives of this study were to describe the overwintering stages of $A$. coregoni; to explore the potential microhabitats and describe the spatial distribution of overwintering stages; and, if overwintered eggs were found, to study their hatching dynamics in the laboratory.

\section{MATERIALS AND METHODS}

Study site. Argulus coregoni was studied at a large commercial fish farm in Central Finland. The fish farm is supplied with water from a lake through 2 canals. One of the canals (I) brings water into a number of ponds containing brown trout Salmo trutta, rainbow trout Oncorhynchus mykiss and Atlantic salmon Salmo salar. The other canal (II) is a raceway divided with grids into 9 sections and used to maintain a stock of $2+$ O. mykiss. Excess water from some of the ponds drains into canal II, which is 1.5 to $2 \mathrm{~m}$ deep with steep walls and a bottom covered with sand, mud and stones. The water temperature during the second half of May varied from 9 to $13.9^{\circ} \mathrm{C}$ in 1999 and 11 to $14.8^{\circ} \mathrm{C}$ in 2000 . The water flow rate during the same period was $1050 \mathrm{l}$ $\mathrm{s}^{-1}$ in 1999 and $1100 \mathrm{l} \mathrm{s}^{-1}$ in 2000. The dissolved oxygen concentration was between 6 and $8 \mathrm{mg} \mathrm{l}^{-1}$ in both years.

Three sections of canal II were studied in 1999. Section 1 was treated in the previous summer (1998) (gravid females were removed mechanically from fish placed into salt water [ $2 \%$ solution of $\mathrm{NaCl}]$ ). Section 2 was untreated and section 3 (situated downstream from section 2) did not contain fish.

The farm also possesses earth ponds of $100 \mathrm{~m}^{2}$ (1 to $1.5 \mathrm{~m}$ deep). Their bottoms are covered with mud, sand and stones. The ponds are flow-through systems with a very low current (10 to $25 \mathrm{l} \mathrm{s}^{-1}$ ). Their oxygen concentration is slightly lower ( 5 to $6 \mathrm{mg} \mathrm{l}^{-1}$ ) and their water temperature usually slightly higher than those in the canal.

Sampling. From 15 to 29 May 1999, when the water temperature increased from 9 to $13.9^{\circ} \mathrm{C}, 320$ overwintered fish from different sections of the canal and ponds (196 rainbow trout, 68 brown trout and 56 Atlantic salmon) were immobilized with MS-222 and checked for the presence of argulid.

Stones from both the deep (1.5 to $2.0 \mathrm{~m}$ ) and shallow ( 0.4 to $0.6 \mathrm{~m}$ depth) parts of canal II, sections 1 to 3 and a pond were sampled by a scuba diver. Sixty stones were inspected from each habitat in the pond and sec- tions 1 to 3 of canal II for the presence of egg clutches. A total of 380 stones were checked. The length, width and height of each stone and the length and width of the clutches found were measured. The surfaces areas were calculated by assuming the stones to be parallelepipeds. Egg clutches were considered to be oval in shape.

To assess potential viability of eggs, 15 randomly chosen egg clutches from the deep and 15 from the shallow parts of canal II sections 1 (where fish were bred) and 3 (a site in the canal where no fish were bred, but that was downstream from sections with $2+$ rainbow trout) were inspected under a dissecting microscope. Within each clutch, 30 eggs were assessed and classified as either viable or unviable. The latter category consisted of visually damaged eggs: they were dark, shrunken or just empty shells.

Samples of mud and sand from the bottom of canal II sections 1 to 3 and the pond were taken with a scoop. To stimulate the hatching of buried eggs the samples were placed for $2 \mathrm{wk}$ in shallow tanks under about $5 \mathrm{~cm}$ of water.

Hatching experiments. We noted that egg clutches on the stones were sometimes covered with mud or sand. Could they retain their viability after being buried for a long time? To answer this question, 60 stones with overwintered egg clutches were collected from canal II section 1 on 8 June 1999, placed in groups of 15 in 4 plastic boxes, covered either with sandy mud ( 2 boxes) or gravel with sand ( 2 boxes), and put on the bottom of the canal. To prevent washing up of the substrata, each box was covered with a net. Before eggs were put into the canal, a sample was examined under a dissecting microscope and another sample was kept in the laboratory at $20^{\circ} \mathrm{C}$ under daylight illumination. Both tests proved that most of the eggs were viable. The stones with buried eggs were excavated on 19 May 2000 after the second overwintering period and held at room temperature with illumination from a white fluorescent tube (Philips TLD 58w/33) (photoperiod: 14:10 h light:dark) to stimulate hatching. The eggs were checked and the water replaced every second day.

The hatching dynamics of normally overwintered eggs from canal II sections 1 and 2 were studied under the same conditions in the laboratory in 2000.

Our pilot observations showed that the percentage of empty egg-shells was higher in the shallow than in the deep habitats. More light reached the bottom in shallow areas of the fish farm, and the eggs there were more illuminated (and received more UV illumination). Furthermore, diurnal temperature fluctuations were more pronounced.

To follow the hatching of eggs and to estimate how hatching is affected by illumination and variation in 
Table 1. Experimental treatment of overwintered eggs of Argulus coregoni. NORM: illuminated by a white fluorescent tube; UV: white fluorescent tube together with a UV tube. Temperature regimens: constant temperature of $20^{\circ} \mathrm{C}$ and temperature varying from $20^{\circ} \mathrm{C}$ during the day to $7^{\circ} \mathrm{C}$ at night. The number of replicates (separate dishes) is indicated

\begin{tabular}{|lcccc|}
\hline \multirow{2}{*}{ Source of eggs } & \multicolumn{2}{c}{ NORM } & \multicolumn{2}{c|}{ UV } \\
& $20^{\circ} \mathrm{C}$ & $20-7^{\circ} \mathrm{C}$ & $20^{\circ} \mathrm{C}$ & $20-7^{\circ} \mathrm{C}$ \\
\hline Pond & 4 & 4 & 4 & 4 \\
Canal section 1 & 2 & 2 & 2 & 2 \\
Canal section 2 & 4 & 4 & 4 & 4 \\
Canal section 3 & 2 & 2 & 2 & 2 \\
\hline
\end{tabular}

temperature, collected egg clutches were subjected to various laboratory treatments (Table 1). Egg clutches from the deep part of 3 sections of canal II and also from a pond collected at the end of May 1999, were scraped from the stones and kept in transparent dishes with $200 \mathrm{ml}$ of filtered (100 $\mu \mathrm{m}$ mesh size) lake water. Each experimental dish contained approximately $4 \mathrm{~cm}^{2}$ of egg plates. Hatching was monitored for $2 \mathrm{wk}$. Newly hatched larvae were counted and removed, and water was replaced daily. 'Normal' illumination was provided with a white fluorescent tube (Philips TLD 58w/33) (photoperiod: 14:10 h light:dark). UV-enriched illumination was provided from $11: 00$ to $15: 00 \mathrm{~h}$ by a combination of UV light from a 20 W Dala Samhall fluorescent tube and the white tube illumination. The overall intensity of illumination in both treatments was 900 lux. The temperature in the incubation room was kept at $20 \pm 1^{\circ} \mathrm{C}$. To mimic temperature fluctuations in shallow waters, some experimental boxes were placed into a dark room at $7^{\circ} \mathrm{C}$ for $8 \mathrm{~h}$ every day.

\section{RESULTS}

\section{Overwintered stages and their spatial distribution}

Neither overwintered adults nor juvenile Argulus coregoni were found on 320 inspected specimens of brown trout, rainbow trout and salmon.

Clutches of overwintered eggs were found on stones in the different sections of canal II and the ponds. However, no larvae hatched from the samples of mud and sand taken from the bottom of the canal and the ponds which were held for 2 wk in the laboratory. Eggs were not found in any of these samples either.

Argulus coregoni egg clutches were found in abundance on stones of various size and shape from the bottom of different sections of canal II where rainbow trout were reared, and from a small pond containing salmon. The greatest proportion of stones covered with
Table 2. Proportion of a stone surface covered with egg clutches and prevalence of stones with Argulus coregoni egg clutches in shallow and deep areas of different sections of canal II and a pond at a fish farm in Central Finland

\begin{tabular}{|lcccc|}
\hline Site & $\begin{array}{c}\text { Depth } \\
(\mathrm{m})\end{array}$ & $\begin{array}{c}\text { No. } \\
\text { stones }\end{array}$ & $\begin{array}{c}\text { Surface covered } \\
(\text { mean } \pm \text { SD } \%)\end{array}$ & $\begin{array}{c}\text { Prevalence } \\
(\%)\end{array}$ \\
\hline Section 1 & 0.5 & 60 & $0.3 \pm 1.7$ & 11.7 \\
Section 1 & 1.5 & 60 & $1.7 \pm 3.8$ & 46.7 \\
Section 2 & 0.5 & 60 & $0.06 \pm 0.3$ & 8.3 \\
Section 2 & 1.5 & 60 & $6.4 \pm 8.3$ & 74.3 \\
Section 3 & 0.5 & 60 & $0.1 \pm 0.5$ & 8.3 \\
Section 3 & 1.5 & 60 & $2.6 \pm 5.1$ & 50.0 \\
Pond & 0.4 & 10 & $0.2 \pm 0.5$ & 27.0 \\
Pond & 1.0 & 10 & $3.6 \pm 8.7$ & 80.0 \\
\hline
\end{tabular}

A. coregoni eggs was found in 1 of the sections (2) of the main canal II (Table 2). Section 1, which was treated the previous summer, and section 3 (without fish) had a significantly lower percentage of stones with $A$. coregoni eggs. In all sections of the canal, deep areas contained stones with eggs 4 to 9 times more prevalent than shallow water areas. The same effect was observed in the pond (Table 2).

The abundance of Argulus coregoni eggs, measured as a proportion of the stone surface covered with eggs, was determined for sections 1, 2 and 3 of canal II and the pond (Table 2). Eggs were much more abundant in the untreated section of the canal (2); the 2 other sections, 1 and 3, contained significantly fewer eggs (Table 2; Kruskal-Wallis ANOVA for the 'canal effect': $H[2, \mathrm{n}=360]=10.15 ; \mathrm{p}=0.006)$. The influence of the depth was even more pronounced (Kruskal-Wallis ANOVA: $H[1, \mathrm{n}=360]=99.60 ; \mathrm{p}<0.0001)$.

A weak but highly significant positive correlation was found between stone size and the proportion of the stone surface covered with eggs (Spearman rank order correlation, $\mathrm{R}=0.22$, $\mathrm{p}<0.0001$ ). Egg clutches were over the entire stone surface, but rarely on surfaces buried in the sediments. However, vertical surfaces were usually more densely covered with clutches than horizontal surfaces. Among the vertically oriented surfaces, those facing downstream had more egg clutches than those facing upstream. The stones harboring the highest numbers of Argulus coregoni eggs were found in areas with the highest egg prevalence; in these areas, parts of some stones were covered 2 or even 3 layers deep with eggs.

Many empty or damaged eggs were observed among the clutches from the canal. The proportion of potentially viable eggs was significantly higher in the deep habitats (mean $=40.2 \pm 38.9 \%$ ) than in the shallow water ones $(13.6 \pm 23.9 \%)$ (Kruskal-Wallis ANOVA: $H[1, \mathrm{n}=58]=8.338, \mathrm{p}=0.004)$. 


\section{Hatching dynamics of overwintered eggs}

Overwintered eggs collected from canal II on 18 May 2000 , when the water temperature was $13^{\circ} \mathrm{C}$, were held at $20^{\circ} \mathrm{C}$ in the laboratory and started to hatch after several hours (Fig. 1). A well-pronounced peak of hatching occurred after several days, after which the hatching rate gradually decreased. After mid-June, eggs hatched only occasionally. However, newly hatched larvae were observed up to the end of August.

The eggs buried under the sediment in spring 1999 for the summer and the second winter were excavated at the end of May 2000 and transferred to the laboratory on the same day as the 'normally' overwintered eggs, but only started hatching in August (Fig. 2). The hatching rate was low and comparable with that of 'normally' overwintered eggs ( 1 to 3 larvae $\mathrm{d}^{-1}$ ) until the end of November, but markedly increased in December.

There was no difference in hatching rate between eggs exposed to night cooling (a lowering of the temperature from 20 to $7^{\circ} \mathrm{C}$ for $8 \mathrm{~h}$ ) and those held at a constant temperature of $20^{\circ} \mathrm{C}$ (Kruskal-Wallis ANOVA: $H$ $[1, \mathrm{n}=24]=0.75 ; \mathrm{p}=0.386$ ).

Additional UV illumination significantly influenced the hatching success of overwintered Argulus coregoni eggs taken from canal II (sections 1 and 2) and the
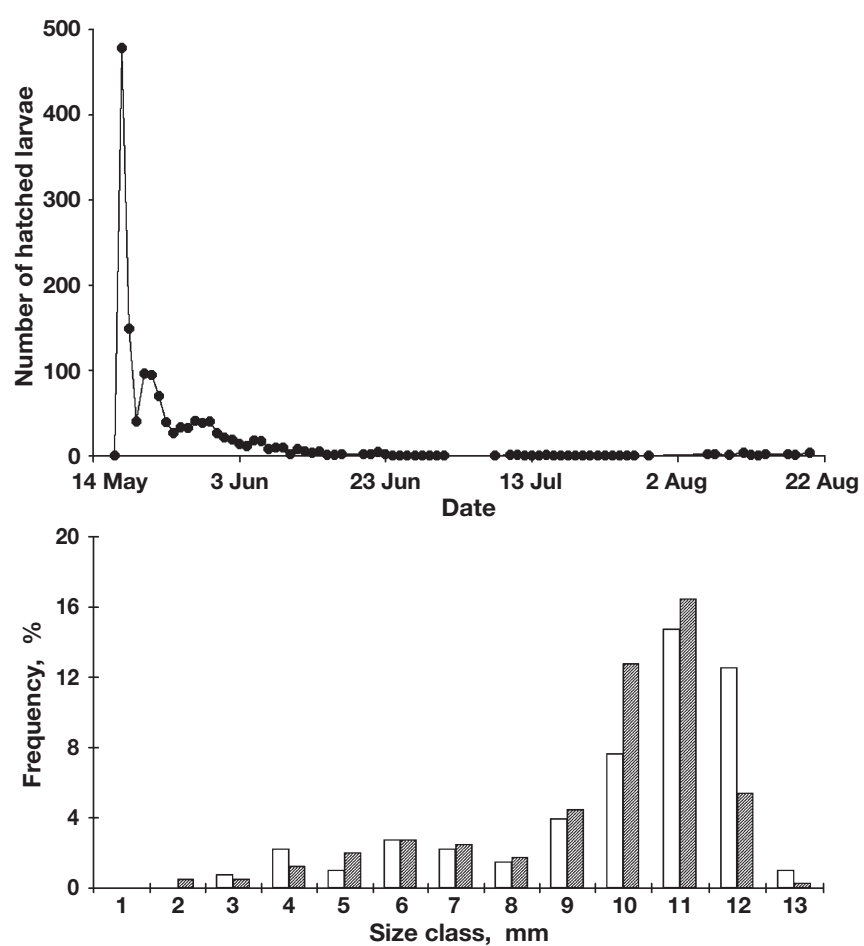

Fig. 1. Spring peak of hatching in Argulus coregoni (upper panel), recognized in a unimodal size-frequency distribution in July (lower panel) (open bars: females; hatched bars: males)

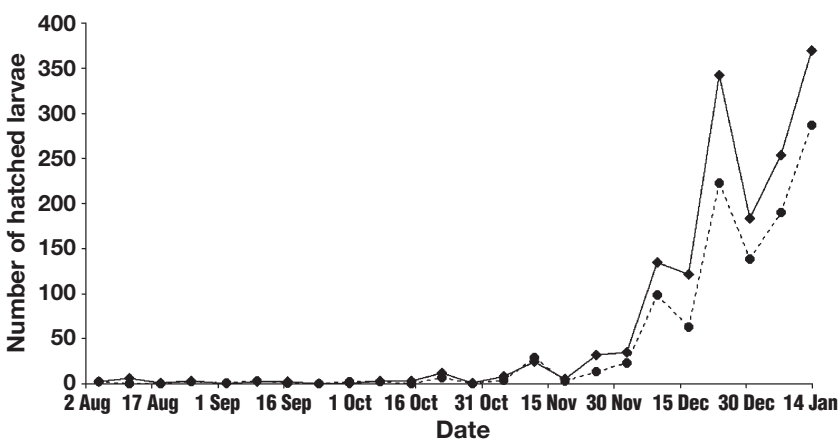

Fig. 2. Hatching of Argulus coregoni larvae from the eggs buried under the sediment from June 1999 to May 2000. Solid line: stones with egg clutches covered with gravel and sand; dashed line: with mud and sand

pond and transferred to the laboratory (Kruskal-Wallis ANOVA: $H[1, \mathrm{n}=24]=5.61, \mathrm{p}=0.0179$ ). During the first $5 \mathrm{~d}$ period of the most intensive hatching, a mean $( \pm \mathrm{SD})$ of $65.0 \pm 39.0$ metanauplii per experimental box was recorded under UV-enriched illumination, while under 'normal' illumination there were, on average, only $29.1 \pm 32.4$ metanauplii per box. The difference between hatching rates was most pronounced at the beginning of the experiment; eventually it decreased (Fig. 3). By the end of the 2 wk experiment there was a marked difference between UV boxes and 'normal' boxes in the total numbers of hatched metanauplii, which were1018 and 628, respectively.

\section{DISCUSSION}

Unike Argulus foliaceus, which lays eggs in shallow water (Kollatsch 1959, Bauer 1970), A. coregoni was found to prefer deeper parts of the canal and ponds for ovipositon. Our finding confirms the experimental data of Shimura \& Egusa (1980), who reported the highest density of $A$. coregoni eggs on artificial substrata sus-

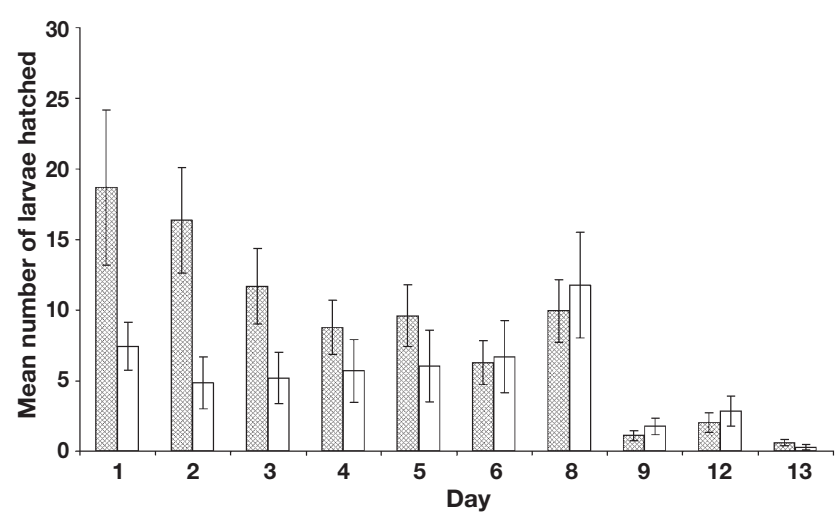

Fig. 3. Hatching dynamics of Argulus coregoni under 'normal' (open bars) and UV-enriched illumination (filled bars) 
pended in the deepest layers of fish ponds. The distribution of the preferred hosts may account for the difference in habitat preference between $A$. foliaceus and $A$. coregoni. Cyprinids and percids, which are the main hosts for A. foliaceus, usually remain in shallow habitats in summer, while salmonids, hosts of A. coregoni, prefer deeper and well oxygenated waters (Kennedy \& Strange 1982, Gardiner 1984). Gravid females detaching from the hosts to lay eggs have to find a suitable substratum in the vicinity.

Larger stones and vertical surfaces were more densely covered with Argulus coregoni eggs. These preferences may be caused by an active choice of substrata clear of sediments; this would also prevent eventual burying of egg clutches. On the other hand, larger stones may be encountered more often, and may be more noticeable and thus more attractive for spawning females. Multi-layer egg laying was observed in the habitats with the maximum percentage of stones bearing eggs; they suggest a possible substrata limitation in the habitats with a high infection rate.

Even though the main pool of deposited eggs was found in the deep parts of the canal, a certain number were laid in shallow water and some were buried under the sediment. The diversity of egg distribution can further extend the prolonged hatching period in argulids (Shafir \& van As 1986, Pasternak et al. 2000).

The pronounced peak of hatching of overwintered eggs lasted in the laboratory for only a few days. The main period of recruitment of Argulus coregoni occurred at the fish farm a week later (the last week of May) and seemed rather restricted. The difference in timing was probably connected to higher water temperature in the laboratory $\left(12\right.$ to $14^{\circ} \mathrm{C}$ in the canal versus $20^{\circ} \mathrm{C}$ in the laboratory). Hatching in $A$. coregoni and $A$. foliaceus was shown to depend strongly on water temperature and never occurred before temperature reached 8 to $10^{\circ} \mathrm{C}$ (Stammer 1959, Shimura 1983). We observed hatching that took place soon after temperature in the canal had reached the critical value of $10^{\circ} \mathrm{C}$. A pronounced cohort of mature adults (10 to $12 \mathrm{~mm}$ body length) that developed from the larvae that hatched at the end of May was recorded in July (Fig. 1, lower panel).

Microscopic examination revealed that there were fewer embryos at the eyed stage in the overwintered eggs buried into the bottom for the second winter than in the normally overwintered eggs. However, those eggs developed and started to hatch in August. There was a peak in the hatching in December. Under natural conditions, they would hatch in mass only the next spring. Thus, accidentally buried eggs can retain their viability for at least $2 \mathrm{yr}$ and may serve as an additional source of recruitment for the Argulus coregoni population. The eggs in the nor- mally overwintered clutches were not homogeneous and not all of them hatched synchronously in spring. We can speculate that the eggs that hatched during the peak were 'programmed' (genetically determined) for early hatching, while those that formed the 'tail' of hatching were programmed for delayed hatching. The eggs that were buried in the sediments would gradually hatch under favorable ambient conditions and have a noticeable probability of survival. Despite a long resting period, these eggs did not hatch soon after they had been excavated. The dynamics of their hatching consists also of a peak and a 'tail', which in this case precedes the peak. Under fluctuating environmental conditions characterized by both abiotic stochasticity and poor predictability of the hosts, an optimal recruitment strategy is to hedge a bet, with a proportion of eggs hatching in a certain period and a proportion remaining dormant, similarly to the model of seed germination (Cohen 1966). Thus, delayed eggs sacrifice their own reproductive prospects to spread the risk over the genotype as a whole (Ellner 1986).

The proportion of empty shells in egg clutches in the spring was greater in shallow than in deeper waters. Temperature and illumination were suggested to have major impacts on hatching (Kollatsch 1959, Shafir \& van As 1986). We considered that the greater illumination with more UV light and more variable temperature in the shallow water habitats were possible factors causing earlier hatching and, as a consequence, the lower proportion of potentially viable eggs on the stones there. However, no effect of fluctuating temperature on hatching was observed in this study. An increase in UV illumination considerably accelerated hatching. This may have an adaptive value during the natural spring water temperature increase when salmonid juveniles tend to be closer to the shore.

Life-history strategies and biological traits in parasites are as diverse as in free-living organisms, and more than 1 strategy can lead to high fitness levels (Poulin 1998). Argulus foliaceus was actually shown to employ 2 overwintering strategies, as adults and as resting eggs (Pasternak et al. 2000). In A. coregoni, however, we have not found alternative strategies of survival through the winter, and eggs are the only source of recruitment in spring.

Acknowledgements. The authors gratefully acknowledge the important help of Mrs Anu Haltunen and Ms Tuija Laitinen. Dr R. Siddall kindly checked the English. The exchange of scientists between Finland and Russia was supported by the Academy of Finland, and the study was partly funded by grants from the Russian Foundation for Basic Research to V.M. (99-04-48687) and to A.P. (01-04-48701). 


\section{LITERATURE CITED}

Bauer ON (1970) Parasite diseases of cultured fishes and methods of their prevention and treatment. In: Dogiel VA, Petrushevski GK, Polyanski YuI (eds) Parasitology of Fishes. T.F.H. Publications, Hong Kong, p 265-298

Bower-Shore C (1940) An investigation of the common fish louse, Argulus foliaceus (Linn.). Parasitology 32:361-371

Cohen D (1966) Optimizing reproduction in a randomly varying environment. J Theor Biol 1:119-129

Ellner S (1986) Germination dimorphisms and parent-offspring conflict in seed germination. J Theor Biol 123: 173-185

Gardiner WR (1984) Estimating population densities of salmonids in deep water and streams. J Fish Biol 24:41-49

Hindle E (1949) Notes on the treatment of fish infected with Argulus. Proc Zool Soc Lond 119:79-81

Kennedy GJA, Strange CD (1982) The distribution of salmonids in upland streams in relation to depth and gradient. J Fish Biol 20:579-591

Kollatsch D (1959) Untersuchungen über die Biologie und

Editorial responsibility: Wolfgang Körting,

Hannover, Germany
Ökologie der Karpfenlaus (Argulus foliaceus L.). Zool Beitr 5:1-36

Pasternak AF, Mikheev VN, Valtonen ET (2000) Life history characteristics of Argulus foliaceus L. (Crustacea: Branchiura) populations in Central Finland. Ann Zool Fenn $37: 25-35$

Poulin R (1998) Evolutionary ecology of parasites. Chapman \& Hall, London

Shafir A, van As JG (1986) Laying, development and hatching of eggs of the fish ectoparasite Argulus japonicus (Crustacea: Branchiura). J Zool Lond (A) 210:401-414

Shimura S (1983) Seasonal occurrence, sex ratio and site preference of Argulus coregoni Thorell (Crustacea: Branchiura) parasitic on cultured freshwater salmonids in Japan. Parasitology 86:537-552

Shimura S, Egusa, S (1980) Some ecological notes on the egg deposition of Argulus coregoni Thorell (Crustacea, Branchiura). Fish Pathol 15:43-47 (in Japanese with English summary)

Stammer J (1959) Beiträge zur Morphologie, Biologie und Bekämpfung der Karpfenläuse. Z Parasitenkd 19:135-208

Submitted: February 6, 2001; Accepted: April 4, 2001

Proofs received from author(s): August 29, 2001 